\title{
THE ROTOSTAT AND GONIOSTAT: A TEACHERS' CLASS ROOM DEVICE FOR INSTRUCTION IN PROJECTION.
}

\author{
By Herman Hanstein, \\ Lane Technical High School, Chicago.
}

One of the most difficult tasks in the instruction of Projection is to demonstrate to the student how the mathematical outlines

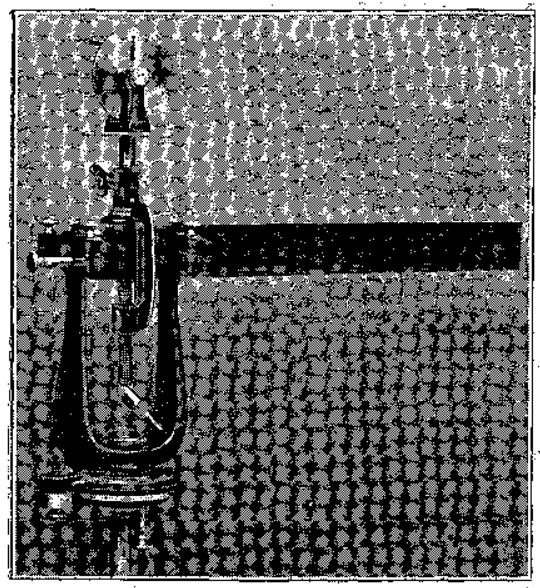

Rotostat Mounted by the Goniostat.

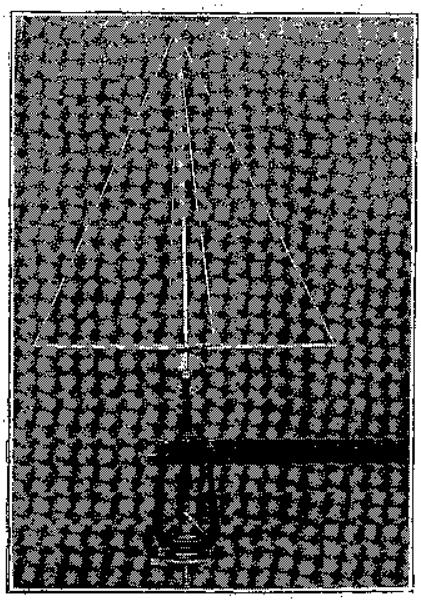

Fig. I. are obtained and drawn on the various planes of projection.

For more than fifty years teachers have used boxes with transparent (glass) sides in which the object to be represented was placed. The foot points of ordinates drawn from every point of these objects to the sides of the box and there connected by lines produced the mathematical outlines of the object-the top view, or plan, the front view, or elevation, and the side views, or side elevations.

Another arrangement to accomplish the same purpose consisted in the substitution of fine wire screens for the glass sides of the box, which permitted the teacher's chalk marks to demonstrate the theories of ordinates from each point of the object to the vertical and horizontal sides of the surrounding box. These equipments will permit only a limited number of students to follow the demonstrations at a time and in large classes it is a serious waste in the modest allowance of time assigned for the instruction of projection on the programs of most of our schools. 
With these arrangements progress in-large classes is very sjow and the need of other equipments with more extended facilities and possibilities is becoming apparent.

The search for efficient means to meet the demands of large classes resulted in the construction of a complete set of models

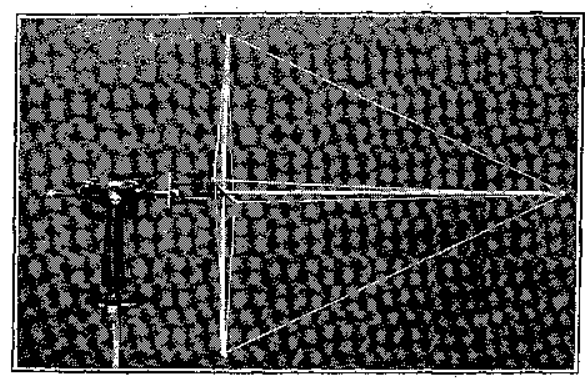

Fig. 2. in skeleton form, each two feet high, light and convenient to handle, with which the regular and an endless number of irregular surfaces, solids and their penetrations may be mounted before the class.

One of these models, the square pyramid, is shown in cut, (Fig. I) inserted with a taper shank in the socket of the goniostat, an instrument having a. vertical and a horizontal axis with divided circles to place the model in any desired position in space. The goniostat is mounted on the horizontal square axis of the rotostat, which permits the rotations of the model and goniostat

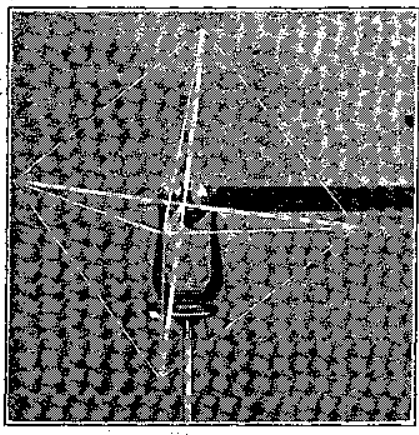

Fig. 3 . in vertical and horizontal planes, with spring stops at quarter revolutions. Fig. I shows the model in its height and widths, the elevation or "front view."

Fig. 2 shows the model rotated in vertical circles forward $90^{\circ}$, and represents its width and depth, the plan or "top view."

The revolutions of the model in horizontal circles are accomplished by the vertical axis of the rotostat, which in Fig. 3 shows side views, or side elevations.

It is the author's intention to give our pupils, with the aid of this device, a substantial and reliable foundation of this most important branch of a technical education-technical drawing.

The practical demonstrations of the models, their analyzation, their sections and penetrations, and their mathematical representations by drawing, soon improves the mental ability of the 
student to "imagine" the existence of an object of any form in any position in space, which ability must be cultivated in the course of the education under discussion, as it forms so important an item in solving the problems that fall within its scope.

This equipment is in successful service in Room $3^{\mathrm{I}} 3$, one of the freshman drawing rooms of the A. G. Lane Technical High School, and colleagtes who are interested in class room devices for the demonstration in geometry and projection are cordially invited to witness its operations during instruction hours and observe the educational results.

\section{PACIFIC COAST ASSOCIATION OF CHEMISTRY AND PHYSICS TEACHERS.}

The semiannual meeting of the association was held at the University of California, Berkeley, on Saturday, July 10, 1909. The attendance at both sessions was excellent and much interest was shown in the discussions. President A. G. Van Gorder delivered an opening address on the organization of science in the high school. Mr. S. E. Coleman of the Oakland High School discussed the question: "What readjustment, if any, is desirable in the physics course of the high school, in view of the changes in university requirements?" General discussion followed. Much interest was manifested in the topic opened by Dr. Winthrop Osterhout of the University of California. This involved the recommendation of a general elementary science course in the first year of the high school and included suggestions as to the purpose and character of such a course. Mr. N. L. Gardner of the Los Angeles Polytechnic High School, gave an account of the general science course as conducted during the past two years under his guidance. In the num. erous opinions presented in general discussion, one idea was frequently expressed: the need for more humanizing of science work in public schools.

The association received an urgent invitation to unite with the American Federation of Teachers of the Mathematical and Natural Sciences. This was accepted without dissenting vote. Dr. William Conger Morgan of the department of chemistry, University of California, was elected to represent the association on the editorial staff of School Sctenoe and Mathematics. In the regular election of officers for the ensuing year, Mr. A. G. Van Gorder was elected president, and Mr. G. C. Barton secretary and treasurer.

At the conclusion of the formal sessions, a very pleasant social time was made pleasanter by a liberal distribution of refreshments. Quite a number of new names were added to the membership roll.

G. C. BARTON, Secretary. 